\title{
Dendrimer-Like PEO Glycopolymers Exhibit Anti-Inflammatory
}

\section{Properties}

\author{
Shyam M. Rele ${ }^{*}$, Wanxing Cui, Lianchun Wang, Sijian Hou, Ginger Barr-Zarse, Daniel \\ Tatton, Yves Gnanou, Jeffrey D. Esko, and Elliot L. Chaikof ${ }^{*}$ \\ Departments of Surgery and Biomedical Engineering, Emory University and School of Chemical \\ and Biomolecular Engineering, Georgia Institute of Technology, Atlanta, Georgia 30322
}

Selectin-induced leukocyte rolling on endothelial surfaces is an essential step in mediating cellular adhesion thereby initiating the complex cascade of events leading to inflammatory and cell-mediated immune responses. ${ }^{1}$ Characteristically, the adhesion cascade is facilitated by the interaction of selectins (L-, P-, E-) with O-glycosylated protein ligands (PSGL-1, CD34 and GlyCAM-1) that present carbohydrate epitopes containing sulfated derivatives of the tetrasaccharide sialyl Lewis x (Neu5Ac $\alpha$ 3Gal $\beta 4$ (Fuc $\alpha 3$ )GlcNAc-, sLe ${ }^{x}$ ). Significant effort has been directed towards generating sLe ${ }^{x}$ mimetics (di-, tri-, tetrasaccharides) in the form of small molecules, polymers, liposomes, and protein conjugates, as competitive inhibitors of selectinmediated binding events. ${ }^{2}$ However, relatively weak affinity $\left(\mathrm{K}_{\mathrm{d}} 0.1-5.0 \mathrm{mM}\right)$, susceptibility to hydrolytic cleavage, potential antigenicity, and short circulating half-life, in addition to the absence of a convenient synthetic route are acknowledged limitations of sLe ${ }^{x}$-derivatized bioconjugates. Thus, motivation exists to develop simpler therapeutic oligosaccharide analogs as selectin-binding antagonists, which structurally resemble naturally occurring saccharide arrays and exhibit multiple and cooperative receptor binding properties.

The simultaneous presentation of multiple copies of biorecognizable saccharide epitopes on an appropriate macromolecular scaffold creates a multivalent display that amplifies the affinity of glycoside-mediated receptor targeting. ${ }^{3,4}$ In this regard, well-defined branched polyethylene oxide (PEO) polymers of tailored size, shape, and geometry provide singularly useful scaffolds for in vivo blockade of selectin binding due to their defined molecular architecture, hydrophilicity, and availability of multiple surface reactive sites. ${ }^{5}$ Moreover, the branched polymer structure also provides a mechanism for controlling accessibility, mobility, density, and supramolecular organization of pendant sugar epitopes, as additional elements that may facilitate the design of optimal selectin-binding antagonists with defined circulating half-life. Herein, we report a simple strategy for the synthesis of $1^{\text {st }}$ and $2^{\text {nd }}$ generation dendrimer-like PEO glycopolymers bearing sulfated $\beta$-lactose as potential L-selectin inhibitors. Most current glycoconjugation strategies describe the use of an aliphatic or aromatic aglycone linker that carries an amine, thiol, thiourea, acid or active ester as the reactive moiety. Significantly, by using imidated lactose donors and a Schmidt glycosidation coupling protocol protecting group manipulations were minimized in the process of glycopolymer synthesis.

Well-defined three $\left(\mathrm{M}_{n} \sim 5200 \mathrm{mu}\right)$ and four arm $\left(\mathrm{M}_{n} \sim 5100 \mathrm{mu}\right)$ PEO stars ( $1^{\text {st }}$ generation) carrying hydroxy end groups, were synthesized by anionic polymerization using "core-first" methodology, as previously reported. ${ }^{6 a, b}$ In addition, a dendrimer-like second generation PEO star polymer (twelve arm) was synthesized based on a phosphazene core. This polymer consisted of a first generation of six PEO arms, produced by an "arm-first" strategy onto the phosphazene core, followed by a second generation of 12 hydroxy-terminated PEO branches 
polymerized directly onto the original 6-arm core $\left(\mathrm{M}_{n} \sim 52 \mathrm{kD}\right) .6 \mathrm{c} \beta$-Lactose octaacetate was selectively brominated at the anomeric centre and subsequently activated to the imidate donor (A).

Glycosylations of hydroxy-terminated PEO star and dendrimer-like polymers by trichloroacetimidate glycosidation methodology, using $\mathrm{BF}_{3} \cdot \mathrm{OEt}_{2}$ as a Lewis acid activator resulted in the covalent attachment of acetyl protected lactose residues in high yield. Zemplen conditions for deacetylation $(\mathrm{NaOMe} / \mathrm{MeOH})$ followed by lactose sulfation using an excess of $\mathrm{SO}_{3}$ trimethylamine complex furnished target $\mathrm{PEO}$ glycoclusters carrying terminal sulfated oligosaccharides 1c, $\mathbf{2 c}$, and 3c. The efficiency, homogeneity, and degree of ligand (lactose) loading on the PEO polymers was estimated by ${ }^{1} \mathrm{H}$ NMR spectroscopy, as well as by mass estimates obtained by MALDI-TOF and laser light scattering. Moreover, FTIR and SDS-PAGE analysis provided additional evidence of sulfated lactose units (See supplementary information).

Specifically, the relative intensities of the anomeric H:Ac: $\mathrm{CH}_{3}$ signal ratio of 6:20.9:3 for the three arm (1a) derivative and an integration ratio of 7.95:27.97:8 for the four arm glycocluster 2a, indicated complete glycosylation of the hydroxyl groups on the parent PEO precursor. The increase in molecular weight was further corroborated using MALDI-TOF (1a: 6899 mu, 2a: $7524 \mathrm{mu}$ ) and LLS measurements confirming quantitative functionalization. Likewise, an NMR integration ratio of 3.9:13.7:3, as well as MALDI-TOF demonstrated a high degree of lactose conjugation (> 95\%) onto the dendritic PEO scaffold of the 12 -arm, $2^{\text {nd }}$ generation, branched compound. Subsequent deprotection followed by sulfation produced a highly charged sulfated glycodendron 3c (observed SELDI-TOF: $61.8 \mathrm{kD}$, expected value $\sim 62 \mathrm{kD}$ ).

Recent investigations have demonstrated that heparin exhibits anti-inflammatory properties by mediating blockade of L- and P-selectins via sulfate dependant interactions. ${ }^{7}$ Moreover, in vitro observations have illustrated that sulfated esters promote selectin binding when appropriately orientated on a lactose core. For example, a sulfated lactose derivative (6,6'disulfo lactose), lacking in fucose and sialic acid residues, was a superior to $\mathrm{SLe}^{x}$ as an in vitro inhibitor of L-selectin binding to GlyCAM-1 ${ }^{8}$ Since selectin-glycoligand binding is greatly amplified through multivalent presentation of oligosaccharide determinants, we explored the capacity of sulfated branched star and dendrimer-like glycopolymers to limit inflammatory responses in vivo via presumed selectin-dependant blockade. Acute peritoneal inflammation was induced in a mouse model by thioglycollate injection into the peritoneal cavity. Test compound potency was valence-dependant with glycopolymers 1c/2c exhibiting little activity, while $3 \mathbf{c}(0.5 \mathrm{mg} /$ mouse IV) dramatically reduced neutrophil and macrophage recruitment by $86 \%$ and $60 \%$, respectively (Fig. $4, \mathrm{p}<0.05$ ). Although heparin inhibited inflammatory cell recruitment to a similar degree, concurrent anticoagulant effects limit heparin's clinical applicability. In contrast, 3c, does not exhibit anti-thrombin activity (data not shown). The ability of 3cto inhibit the adhesion of U937 lymphoma cells to immobilized P-, L- or E-selectins was examined, in order to determine whether the observed in vivo effect was mediated by presumed selectin blockade. Test compound 3c selectively blocked the adhesion of U937 cells to L-selectin in a dose dependent manner $\left(\mathrm{IC}_{50}=2.4 \mathrm{nM}\right)$, but did not exhibit anti-P-selectin or E-selectin activity (Fig. 5). Therefore, $\mathbf{3 c}$ is among the most potent L-selectin inhibitors yet reported. ${ }^{2 \mathrm{a}, 8,9,10}$ Significantly, precedence exists for increased biological activity as a consequence of ligand presentation by dendrimeric scaffolds when compared to linear counterparts. ${ }^{2 b}$ Despite significant anti-L-selectin activity, the observed in vivo activity was surprising, since it has been recently reported that heparin's anti-inflammatory activity in vivo is critically dependant on its ability to inhibit both L- and P-selectin mediated inflammatory cell adhesion. ${ }^{7}$ Indeed, a compound acting solely as a selective inhibitor of L-selectin is not anticipated to block in vivo leukocyte infiltration so completely. Thus, it is likely that $\mathbf{3 c}$, like 
heparin, blocks chemokine binding to the endothelium, which would further limit leukocyte extravasation.

In summary, a new class of high molecular weight polysulfated PEO dendrimer-like glycopolymer has been synthesized by a combination of arm-first and core-first methodologies followed by trichloroacetimidate glycosidation as a facile bioconjugation strategy. This is the first report to describe the synthesis and biological evaluation of complex branched PEO heparinoid-mimics, which provides an easily accessible route to carbohydrate-based compounds with anti-inflammatory activity in vivo.

\section{Supplementary Material}

Refer to Web version on PubMed Central for supplementary material.

\section{Acknowledgements}

This work was supported by NIH grants HL57345 to JDE and HL60464 to ELC.

\section{References}

1. (a) Ulbrich H, Eriksson E, Lindbom L. Trends Pharmacological Sc 2003;24:640-647. (b) Ley K. Trends Molecular Med 2003;9:263-268. (c) Hopfner M, Alban S, Schumacher, Rothe U, Bendas G. J Pharmacy and Phamacology 2003;55:697-706. (d) Lowe JB, Ward PA. J Clin Invest 1997;99:822826. [PubMed: 9062337]

2. (a) Sanders WJ, Gordon EJ, Oren D, Beck PJ, Ronen A, Kiessling LL. J Biol Chem 1999;274:52715278. [PubMed: 10026133] (b) Reuter J, et al. Bioconjugate Chem 1999;10:271-278. (c) Lin C-C, Kimura T, Wu S-H, Weitz-Schmidt G, Wong C-H. Biorg Med Chem Lett 1996;6:2755-2760. (d) Spevak W, Foxall C, Charych D, Dasgupta F, Nagy JO. J Med Chem 1996;39:1018-1020. [PubMed: 8676335] (f) DeFrees SA, Phillips L, Guo L, Zalipsky S. J Am Chem Soc 1996;118:6101-6104. (g) Manning DD, Strong L, Hu X, Beck P, Kiessling LL. Tetrahedron 1997;53:11937-11952. (h) Thoma G, Duthaler RO, Magnani JL, Patton JT. J Am Chem Soc 2001;123:10113-10114. [PubMed: 11592897] (e) Barbaro J. Curr Org Chem 2004;8:883-902.

3. (a) Lundquist JJ, Toone EJ. Chem Rev 2002;102:555-578. [PubMed: 11841254] (b) Mammen M, Choi SK, Whitesides GM. Angew Chem, Int Ed 1998;37:2754-2794.

4. (a) Aoyama Y. Chem-Eur J 2004;10:588-593. (b) Casnati A, Sansone F, Ungaro R. Acc Chem Res 2003;36:246-254. [PubMed: 12693922] (c) Shaunak S, et al. Nat Biotechnol 2004;22:977-984. [PubMed: 15258595]

5. (a) Frey H, Haag R. Rev Mol Biotech 2002;90:257-267. (b) Zalipsky S. Adv Drug Delivery Rev 1995;16:157-182.

6. (a) Hou S, Chaikof E, Taton D, Gnanou Y. Macromolecules 2003;36:3874-3881. (b) Angot S, Taton D, Gnanou Y. Macromolecules 2000;33:5418-5424. (c) Hou S, Taton D, Saule M, Logan J, Chaikof E, Gnanou Y. Polymer 2003;44:5067-5074.

7. Wang L, Brown J, Varki A, Esko J. J Clinical Invest 2002;110:127-136.7. [PubMed: 12093896]

8. (a) Bruehl R, Bertozzi C, Rosen S. J Biol Chem 2000;275:32642-32648. [PubMed: 10938267] (b) Rosen D. Am J Pathal 1999;155:1013-1020. (c) Galustian C, Lubineau A, le Narvor C, Kiso M, Brown G, Feizi T. J Biol Chem 1999;274:18213-18217. [PubMed: 10373422]

9. (a) Roy R, Park WC, Zanini D, Foxall C, Srivastava OP. Carbohydr Lett 1997;2:259. (b) Mowery P, Yang Z-Q, Gordon ED, Beck, Spencer A, Alon R, Kiessling L. Chem \& Biol 2004;11:725-732. [PubMed: 15157883]

10. Xie X, Rivier AS, Zakrzewicz A, Bernimoulin M, Zeng XL, Wessel HP, Schapira M, Spertini O. J Biol Chem 2000;275:34818-34825. [PubMed: 10944519] 


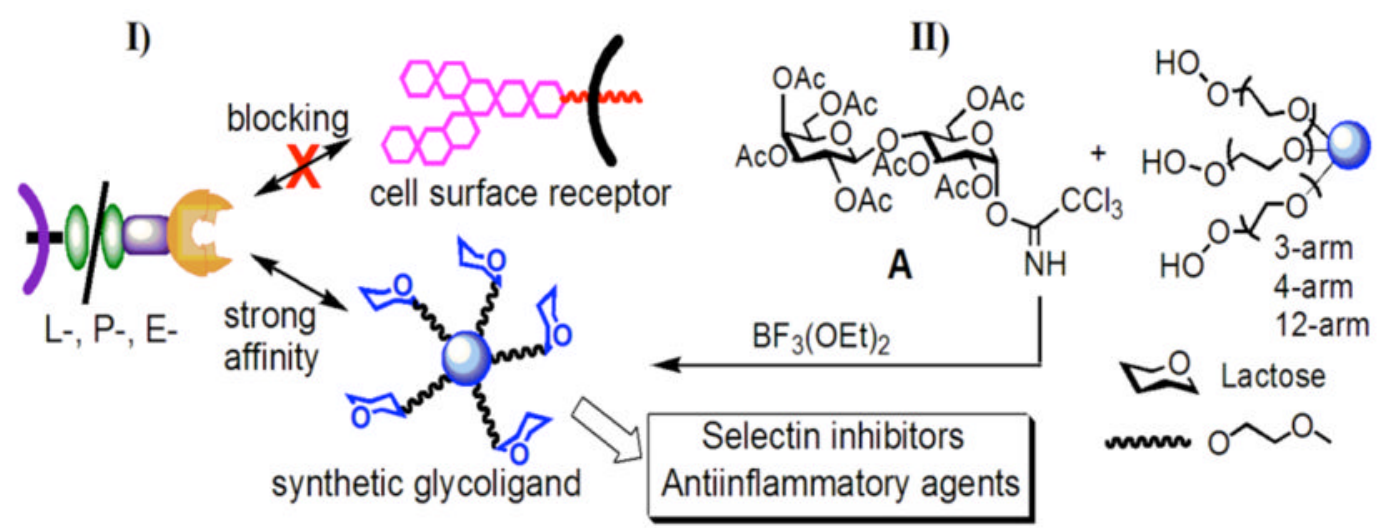

Figure 1.

I) Selectin blockade using polyvalent branched glycoconjugates. II) Glycosidation of terminal hydroxyls on a PEO scaffold using lactose imidate (A). 

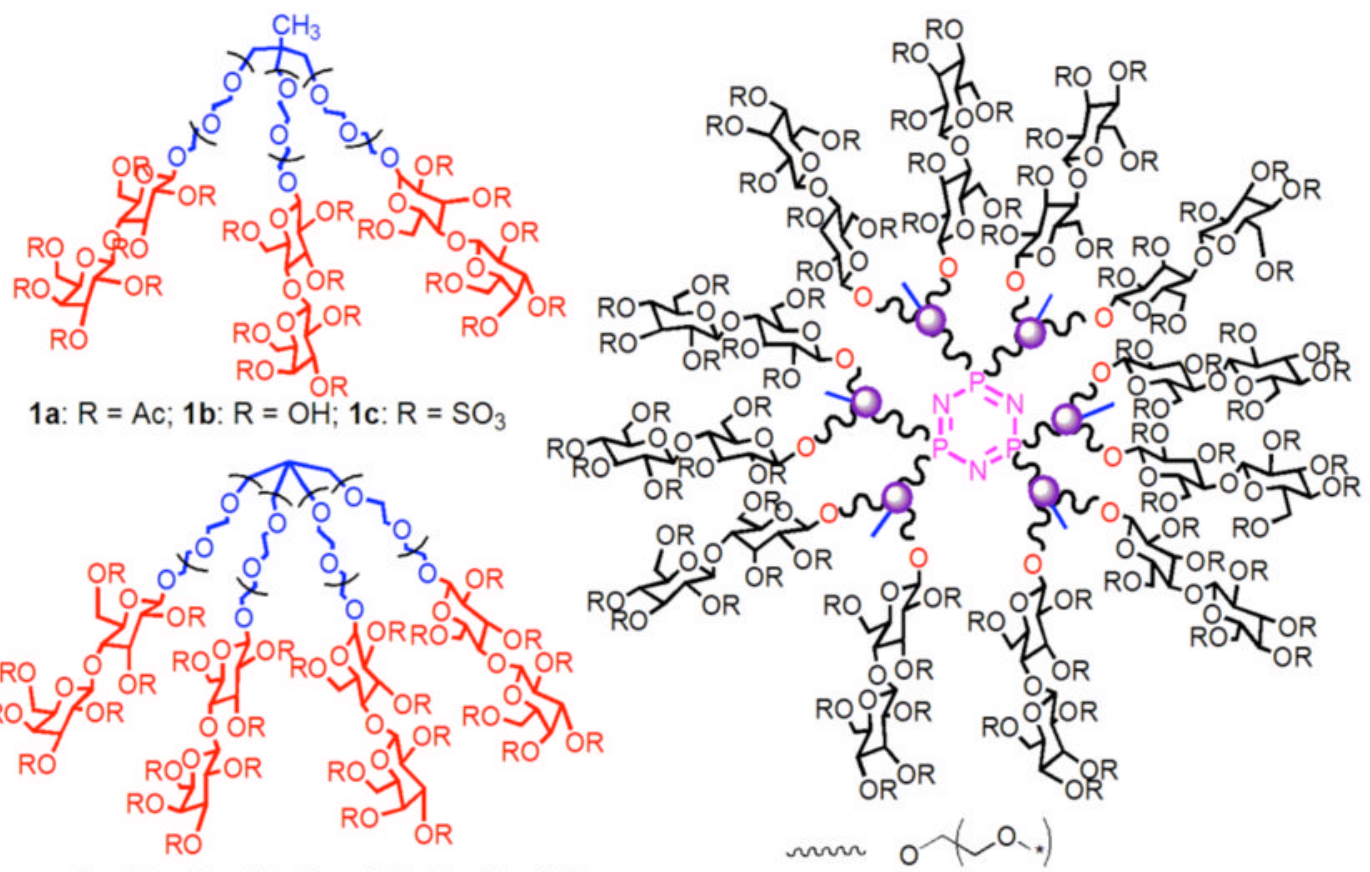

2a: $\mathrm{R}=\mathrm{Ac} ; \mathbf{2 b}: \mathrm{R}=\mathrm{OH} ; \mathbf{2 c}: \mathrm{R}=\mathrm{SO}_{3}$

1st generation

3a: $\mathrm{R}=\mathrm{Ac} ; 3 \mathbf{b}: \mathrm{R}=\mathrm{OH} ; 3 \mathbf{c}: \mathrm{R}=\mathrm{SO}_{3}$ 2nd generation

Figure 2.

Saccharide-functionalized PEO star and 'dendrimer-like' polymers as selectin ligands. 
Integral Ratio:

expected anomeric $\mathrm{H}: \mathrm{Ac}: \mathrm{Me} \quad 4.0: 14.0: 3.0$

found anomeric $\mathrm{H}: \mathrm{Ac}: \mathrm{Me} \quad 3.9: 13.7: 3.0$
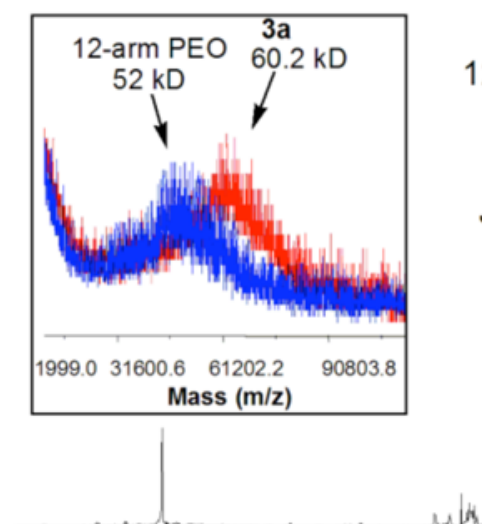

$12 \times 2$ anomeric $\mathrm{H}^{-\mathrm{CH}_{2} \mathrm{CH}_{2} \mathrm{O}-}$

$\mathrm{H} 1+\mathrm{H} 1{ }^{\prime}$

$J=8 \mathrm{~Hz}$ $J=8 \mathrm{~Hz}$

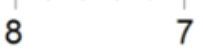

7

6

Wh

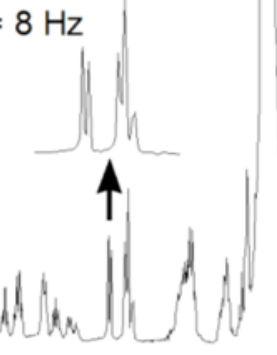

4

5

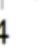

3

$12 \times 14 \mathrm{Ac}$

Figure 3.

$600 \mathrm{MHz}{ }^{1} \mathrm{H}$ NMR spectrum of $\mathbf{3 a}$ ( $2^{\text {nd }}$ generation, 12 end groups) recorded in $\mathrm{CDCl}_{3}$ at $25^{\circ}$ C. Inset shows the MALDI-TOF spectra of the original hydroxyl-terminated phosphazene corebased PEO branched polymer and glycodendrimer 3a, confirming a high degree of sugar conjugation. 

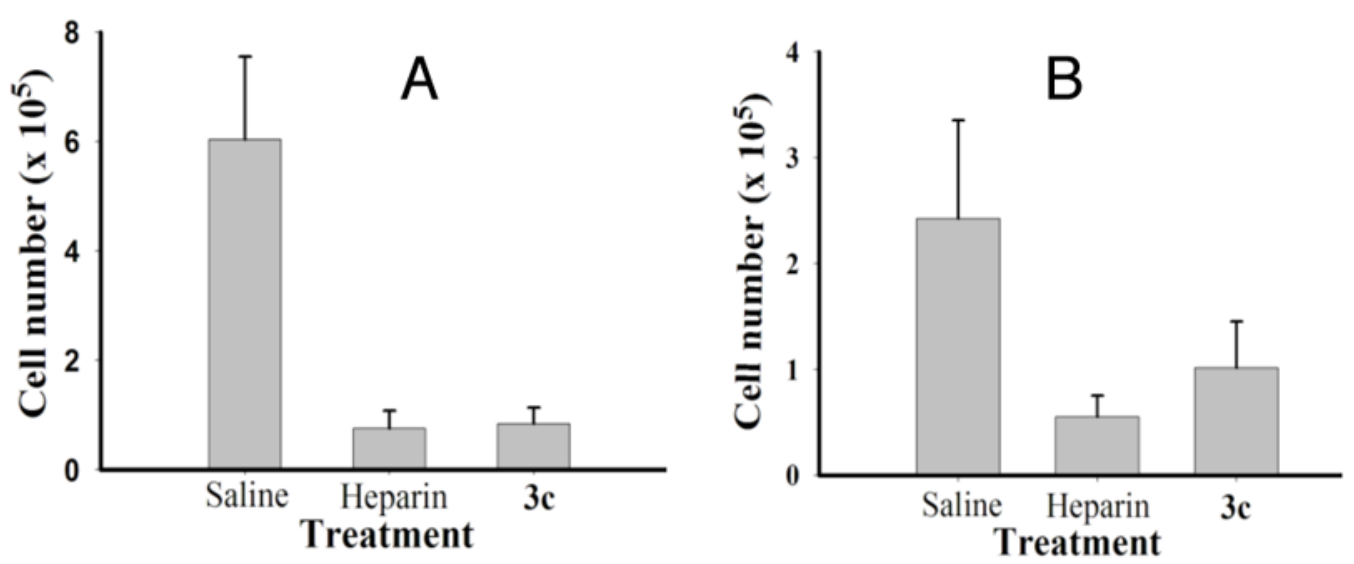

Figure 4.

Neutrophil and macrophage content in thioglycollate-induced peritoneal inflammation $(n=6)$. A: Neutrophil. B: Macrophage. Significant differences were observed in neutrophil and macrophage content in mice treated with heparin and $\mathbf{3 c}$ compared with control mice that received saline ( $\mathrm{p}<0.05$ ). Compounds $\mathbf{1} \mathbf{c} / \mathbf{2 c}$ did not exhibit in vivo activity. Each bar represents the average value $\pm \mathrm{SD}$. 

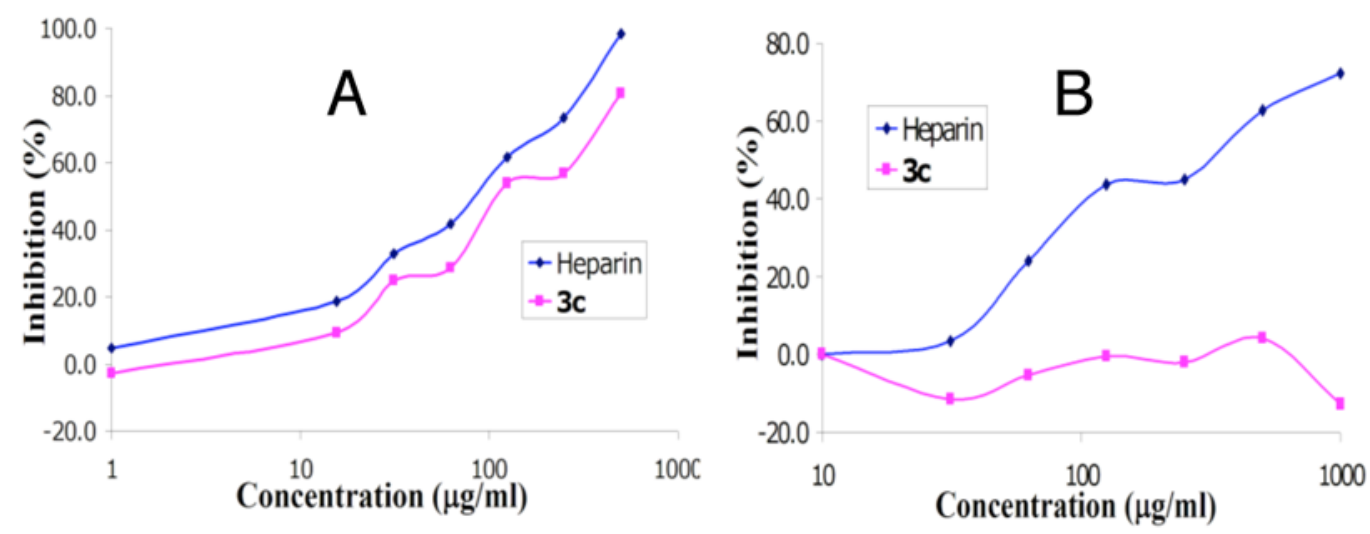

Figure 5.

Competitive inhibition of U937 cell adhesion to immobilized A) L- selectin, B) P-selectin. Neither heparin nor $\mathbf{3 c}$ exhibited inhibitory activity towards E-selectin. Inhibition was not observed in the absence of test compound or heparin. Data represents means of at least $n=3$, $\mathrm{SD}<10 \%)$. 